\title{
Molecular epidemiology of recurrent clinical mastitis due to Streptococcus uberis: Evidence of both an environmental source and recurring infection with the same strain
}

\author{
Salem Abureema, ${ }^{*}$ Peter Smooker, ${ }^{*}$ Jakob Malmo, $†$ and Margaret Deighton ${ }^{* 1}$ \\ *School of Applied Sciences, Royal Melbourne Institute of Technology (RMIT) University, Bundoora, Victoria 3083, Australia \\ †Maffra Veterinary Centre, Maffra, Victoria 3860, Australia
}

\section{ABSTRACT}

This study was undertaken because clinicians and farmers have observed that a considerable number of cows diagnosed with Streptococcus uberis mastitis have recurrences of mastitis in the same or a different quarter. The study was an attempt to answer whether these recurring cases were due to treatment failure (in which case a search would have begun for a better treatment for Strep. uberis mastitis) or due to reinfection with a different strain of Strep. uberis. Using pulsed-field gel electrophoresis (PFGE), we determined that the majority of recurrences (20 of 27) were caused by a new strain of Strep. uberis, indicating that treatment of the initial infection had been successful. A small number of recurrences ( 5 of 27) were caused by the initial strain, indicating persistence. The remaining 2 recurrences occurred in a new quarter but with the initial strain of Strep. uberis, indicating either spread between quarters or reactivation of a previous subclinical infection. Analysis of the PFGE profiles failed to reveal any strainspecific propensity to persist, because strains causing recurrences occurred in most of the major clusters.

Key words: Streptococcus uberis, recurrent clinical mastitis, pulsed-field gel electrophoresis

\section{INTRODUCTION}

Mastitis is one of the most important infectious diseases of dairy cattle, with Streptococcus uberis being among the 5 most common bacterial species involved (Leigh, 1999; Bradley, 2002; Shum et al., 2009; Charman et al., 2012). A recent survey of mastitis pathogens in the southeastern Australian dairy industry showed that $33 \%$ of the clinical mastitis samples submitted for culture yielded Strep. uberis (Charman et al., 2012). Although some cows have single infections, second or subsequent infections with a new strain or the same strain of Strep. uberis are not uncommon (Jayarao

Received May 29, 2013.

Accepted September 12, 2013.

${ }^{1}$ Corresponding author: margaret.deighton@rmit.edu.au et al., 1993; Wang et al., 1999; Douglas et al., 2000; Phuektes et al., 2001; Khan et al., 2003; McDougall et al., 2004, Pullinger et al., 2007).

Currently, intramammary antibiotics are widely used to control mastitis due to Strep. uberis; however, treatment is not universally successful (McDougall et al., 2004; Coffey et al., 2006). Moreover, because attempts at vaccination against mastitis caused by Strep. uberis have not been successful, the need exists for better control of this type of mastitis based on a detailed knowledge of transmission patterns (Leigh et al., 1999).

Pulsed-field gel electrophoresis (PFGE) is a useful method for studying the epidemiology of bacterial pathogens, because it can detect rapidly evolving genetic changes, reflecting short-term epidemiology (Coffey et al., 2006; Li et al., 2009). Studies undertaken in different dairying countries have shown a wide variety of PFGE types of Strep. uberis present on a single farm, suggesting an environmental source. There are also instances of the same strain being isolated from different cows and of second and subsequent infections occurring with the same or a different strain (Table 1). The studies listed in Table 1 sourced isolates from cases of both clinical and subclinical cases of mastitis. None of these studies specifically examined the epidemiology of clinical mastitis in cows having more than one episode of infection with Strep. uberis.

The main purpose of this study was to determine whether repeated episodes of clinical mastitis, in which Strep. uberis was isolated from both the initial infection and from subsequent infections, were associated with the same strain of Strep. uberis (possibly indicating treatment failure, strain-specific persistence, or transmissibility) or were associated with different strains, indicating a new infection, possibly because of greater susceptibility of some cows to infection.

\section{MATERIALS AND METHODS}

\section{Study Design}

This study used stored isolates of Strep. uberis from an earlier study (Runciman et al., 2010). Seven farms 


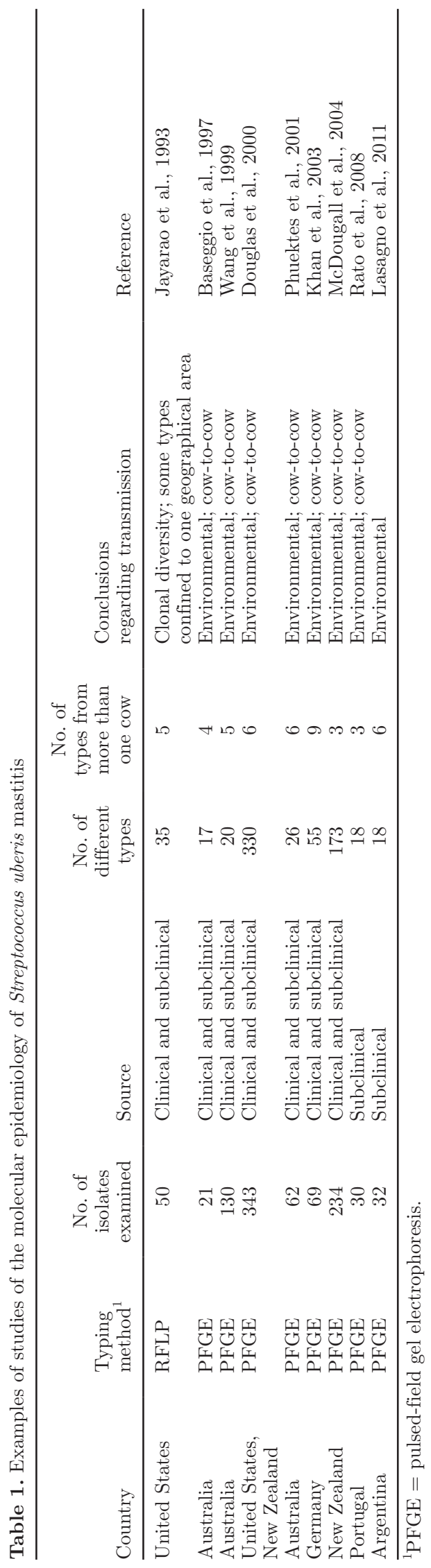

in the Maffra district of Gippsland, Victoria, Australia were enrolled in the study, with sample collection commencing with the beginning of the spring calving period. The farmers were selected on the basis that they would be willing to collect milk samples from clinical cases of mastitis using previously demonstrated aseptic techniques and to keep good records and because they were known to be cooperative in such studies. Three of the farms were strict seasonal-calving farms (with all cows calving between August and October) and the other 4 farms were split-calving herds (a large percentage of the cows calving in August, September, and October, with a smaller percentage calving in March, April, and May). Farmers were asked to collect milk samples from as many of their clinical cases of mastitis as was practicable. Samples were collected by the farmers from cows that the farmers diagnosed as suffering from clinical mastitis, based on signs of changes in the milk (clots, discoloration, or wateriness after the first 3 squirts of milk from the quarter was discarded, with more severe quarters showing signs of heat and swelling in the affected quarter). Sample collection commenced at the start of the spring calving period. Clinical cases of mastitis generally received 3 doses of intramammary cloxacillin (200 $\mathrm{mg}$ of cloxacillin as the benzathine salt in a long-acting base) over $5 \mathrm{~d}$, with a tube inserted on d 1, 3, and 5. Before the commencement of treatment, an aseptically collected milk sample was collected and forwarded to RMIT University (Bundoora, Victoria, Australia) for culture.

\section{Strep. uberis Isolates}

In total, 212 isolates of Strep. uberis were obtained from cases of clinical mastitis and stored at $-80^{\circ} \mathrm{C}$. A chosen subset of 60 Strep. uberis from 27 cows included all isolates from cows with recurrent infections, provided they were obtained from pure cultures showing moderate or heavy growth of Strep. uberis. The subset included isolates from 6 of the 7 farms. On retrieval from storage, the identity of all isolates was confirmed using selected cultural and biochemical tests (carbohydrate fermentation, esculin hydrolysis, and hippurate hydrolysis), serological tests (streptococcal agglutination system containing A, B, C, D, F, and G groupspecific antibodies) and by PCR of 23S rRNA (Hassan et al., 2001), HasA, HasC (Field et al., 2003), and PauA genes (Zadoks et al., 2005a).

\section{PFGE}

Pulsed-field electrophoresis was performed based on methods described previously (Smith and Cantor, 1987; Phuektes et al., 2001). Interpretation of chromosomal 
DNA restriction patterns was based on the criteria of Tenover et al. (1995) as well as analysis by GelCompar II version 6.0 software package (Applied Maths, SintMartens-Latem, Belgium). The PFGE profiles were converted to TIFF files and subjected to cluster analysis using GelCompar II. The lambda molecular weight marker (New England Biolabs, Beverly, MA) was used as reference pattern to normalize all gels. Clustering was based on the unweighted pair group method with arithmetic averages (UPGMA). The similarities of the banding patterns were analyzed using the Dice correlation coefficient. The tolerance position was set at $1 \%$. Isolates indicating more than 3 DNA fragment differences and a similarity of $<80 \%$ upon dendrogram analysis were classified as different PFGE types, whereas fragment variations and a similarity of $>80 \%$ upon dendrogram analysis were defined as PFGE subtypes. Isolates showing identical patterns and a similarity index of $>80 \%$ were interpreted as belonging to the same PFGE type.

\section{RESULTS}

Recurrent clinical mastitis caused by the strain that caused the original episode was defined as persistent infection, whereas recurrent infections with a different strain were defined as reinfections (Döpfer et al., 1999). Of the 27 cows with more than one episode of clinical mastitis with Strep. uberis, 22 cows had 2 episodes, 4 cows had 3 episodes, and 1 cow had 4 episodes over the study period. The duration between the first and second episode ranged from $10 \mathrm{~d}$ to more than $1 \mathrm{yr}$ (into a new lactation period). Based on PFGE analysis, most recurrent episodes of clinical mastitis were reinfections, but some were due to persistence of the original strain (Table 2). Reinfections were identified in 20 cows (14 in a different quarter, 6 in the same quarter), whereas persistent infections occurred in 5 cows. For the 2 remaining cows, the second episode occurred in a different quarter after $10 \mathrm{~d}$ and $5 \mathrm{wk}$, respectively, but with the same PFGE type as the initial episode. Third episodes of clinical mastitis were all reinfections. One cow had 4 episodes of clinical mastitis; the second and third episodes were defined as reinfections and the fourth was considered due to persistence (possibly associated with treatment failure) because it occurred in the same quarter only $2 \mathrm{wk}$ after the third episode and was caused by a new subtype of the third strain. All persistent infections or examples of spread to a different quarter occurred within 1 to 8 wk of the first infection.

Analysis of the 60 isolates revealed 47 PFGE types (including subtypes), clustered into 6 major groups at the $80 \%$ similarity level (Figure 1). Thirty-seven PFGE patterns were represented by single isolates, but 10
PFGE types, which were distributed over all but one of the 6 clusters, appeared in 2 ( 7 types) or 3 (3 types) different isolates. Eight paired isolates were from the same cow, and 5 were from different cows on the same farm $(\mathrm{n}=2)$ or different farms $(\mathrm{n}=3)$. Two of the latter paired isolates involved different subtypes of Strep. uberis, whereas the third involved identical types.

\section{DISCUSSION}

The present study examined the PFGE profiles of Strep. uberis isolates from cases of recurrent clinical mastitis, and found a high degree of heterogeneity among isolates, suggesting that, in most cases, Strep. uberis clinical mastitis arises from the cow's environment. Other studies from different parts of the world, using isolates of Strep. uberis from both clinical and subclinical mastitis (Table 1) or from environmental sources (Zadoks et al., 2005b), reached a similar conclusion. The small proportion of persistent infections observed in most of these studies, including our own, could be explained by cow-to-cow transmission during milking or by infection with a strain of Strep. uberis with enhanced transmission potential or stability in the environment Because the practice in the herds in this study was to graze cattle on pasture, rather than use feedpads or cow barns (where the concentration of fecal bacteria is likely to be greater), the first explanation seems most likely.

Overall, approximately $76 \%$ (25/33; Table 2) of second and subsequent cases of Strep. uberis clinical mastitis were apparent reinfections, generally in a different quarter from the previous infection; therefore, treatment of the initial infection appeared to be effective in most cases. Many factors could explain why recurrent cases of mastitis caused by different strains may have occurred in certain cows. These might include persistent teat-end damage, anatomical characteristics of the teat or teat canal (e.g., cows with more open teat canals; Breen et al. 2009), or reduced host defense mechanisms.

Table 2. Cows with multiple episodes of Streptococcus uberis clinical mastitis

\begin{tabular}{lr}
\hline Type of infection & \\
\hline Second infection & $\begin{array}{c}\text { No. of } \\
\text { cows }\end{array}$ \\
New PFGE type (reinfection) & 20 \\
Identical PFGE type, same quarter (persistence) & 5 \\
Identical PFGE type, different quarter (spread) & 2 \\
Third infection & 5 \\
New PFGE type (reinfection) & 1 \\
Fourth infection & \\
Different subtype, same quarter (probable persistence)
\end{tabular}

${ }^{1}$ PFGE $=$ pulsed-field gel electrophoresis. 


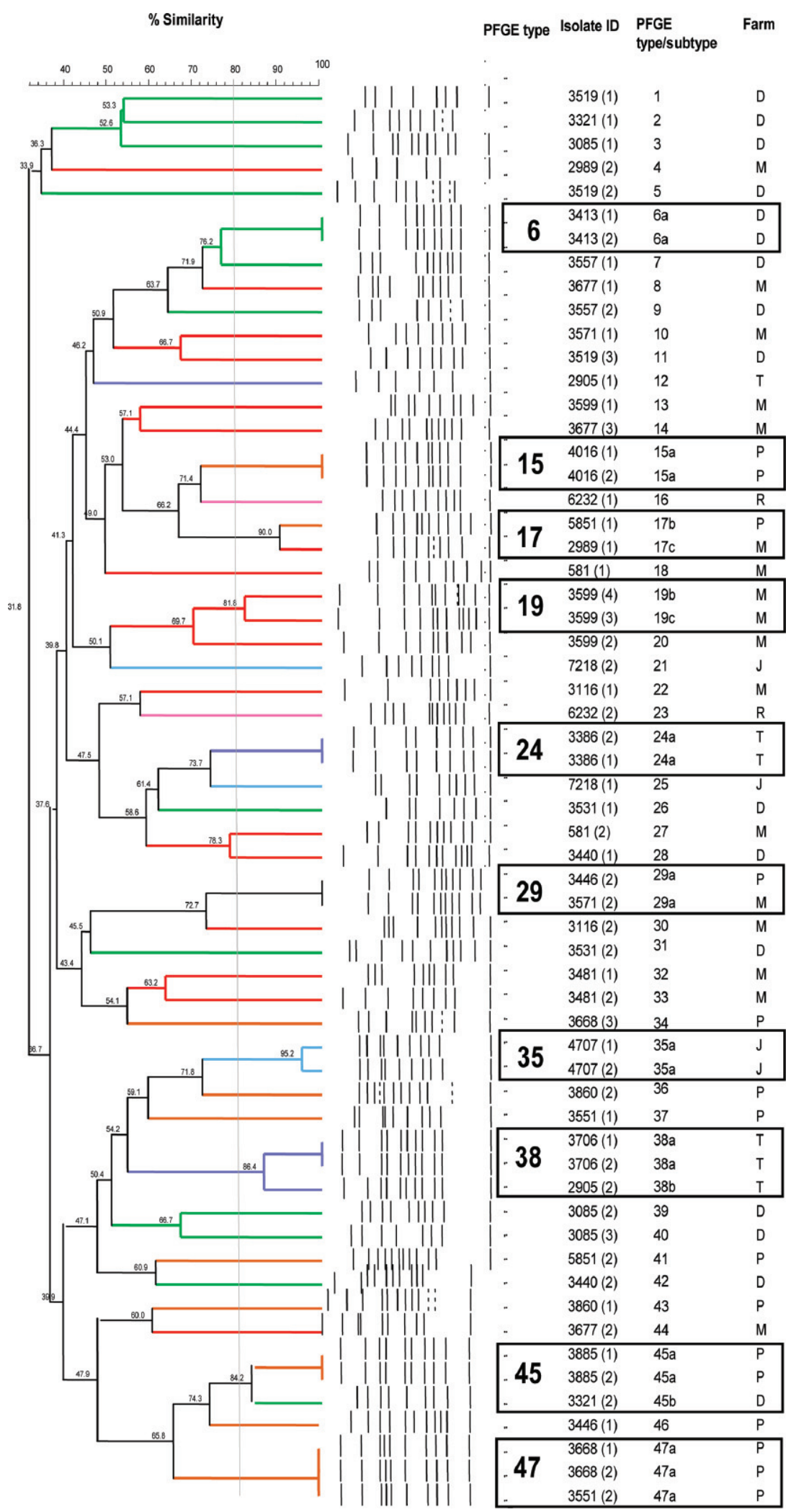

Figure 1. Dendrogram of 60 Australian Streptococcus uberis clinical isolates from cows with more than one episode of clinical mastitis over 1 yr. Farms are represented by letters (and colors): D (green), M (red), T (mauve), P (brown), R (pink), and J (blue). Pulsed-field gel electrophoresis (PFGE) types are indicated by numbers (type) and letters (subtype). For isolate identification, a second or subsequent infection is denoted by number $(2,3,4)$ next to the isolate. Repeatedly isolated PFGE types are enclosed in rectangles. Color version available in the online PDF. 
In these cows, a more effective antimicrobial treatment program is unlikely to be beneficial.

In the 6 episodes of clinical mastitis (5 second infections and 1 fourth infection), the same or a closely related PFGE type was isolated a second time from the same udder quarter within 8 wk of the previous infection. It is likely that the initial clinical signs resolved following treatment but the organisms persisted, only to re-emerge later as clinical mastitis, indicating that bacteriological cure is not always achieved with currently used treatments. Bacteriological cure rates of $>90 \%$ have been reported for clinical Strep. uberis mastitis (McDougall et al., 2007). However, the authors of that paper pointed out that the "true" proportion of bacteriological cures of glands with clinical mastitis was likely to be lower than the estimated bacteriological cure because a proportion of the clinical therapy failures (which were not recultured to test for bacteriological cure) were genuinely likely due to failure of the therapy to produce bacteriological cure. The 2 instances of the same PFGE type being isolated from different quarters of the same cow after periods of $10 \mathrm{~d}$ to 5 wk suggest that treatment of the initial infection was successful, but that Strep. uberis spread between quarters. Alternatively, the second quarter may have been harboring a subclinical infection at the time of the first clinical infection. It is also possible that these apparent persistent infections were reinfections from a common environmental source. Other studies using PFGE or multilocus sequence typing to subtype isolates from collections that included isolates from both clinical and subclinical mastitis reported percentages of paired isolates of the same type ranging from 16 to 100\% (Jayarao et al., 1993; Wang et al., 1999; Douglas et al., 2000; Phuektes et al., 2001; Khan et al., 2003; McDougall et al., 2004; Pullinger et al., 2007). These differences in the proportion of persistent and new infections probably reflect differences in treatment protocols and the proportion of clinical cases (treated) and subclinical cases (untreated) included in the samples.

In agreement with Pullinger et al. (2007), we found no evidence of particular strains having a greater propensity to persist than others, because the PFGE types that caused persistent infections were distributed across all but one of the major clusters (Figure 1). It is therefore likely that host factors, rather than strain, determine whether persistence occurs. These persistent infections are important because they may play a major role as reservoirs of infection in a herd (Phuektes et al., 2001).

The identification of closely related PFGE types of Strep. uberis from clinical cases of mastitis on different farms (Figure 1) is consistent with 2 other studies (Douglas et al., 2000; Lasagno et al., 2011), but the reasons for these findings are not clear. Although isolates used in the present study were from cows in the Maffra district of Gippsland, Australia, cows were not transported between these farms. It is possible that these strains were more prevalent in the environment than other strains. Alternatively, because members of 2 of the 3 pairs of isolates from different farms were subtypes rather than identical PFGE types, they may in fact be different strains, not identified by PFGE.

The PFGE methodology used in this study reflects rapidly evolving genetic changes and therefore identifies recent changes in the Strep. uberis genome ( $\mathrm{Li}$ et al., 2009). It would be interesting to examine the same isolates using multilocus sequence typing to detect slowly accumulating changes in stable housekeeping genes (Feil and Enright, 2004; Coffey et al., 2006; Li et al., 2009) and determine whether strains causing persistent infections belong to unique clonal complexes.

\section{CONCLUSIONS}

We conclude that second and subsequent episodes of Strep. uberis clinical mastitis are commonly caused by new strains acquired from the cow's environment. However, in a small but significant number of recurrent cases, the same or closely related PFGE type was isolated subsequently from the same udder or quarter within 8 wk of the previous infection. In such cases, it is likely that the initial clinical signs resolved after treatment but the organisms persisted, only to re-emerge later as a recurrent case of clinical mastitis. We also found evidence of either direct transmission between cows or infection from a common environmental source. These findings are in agreement with other studies that included isolates from both clinical and subclinical cases of mastitis, although the proportion of types infecting more than one cow differed between studies. These observations indicate that the relative importance of an environmental source and cow-to-cow transmission in the occurrence of mastitis may depend on different management practices, geographical factors, and the transmissibility and disease potential of the particular strains circulating in the cow's environment. Attention to possible environmental sources of infection, good standards of milking hygiene, and proper treatment of Strep. uberis mastitis remain important measures in attempts to control transmission of Strep. uberis.

\section{ACKNOWLEDGMENTS}

Salem Abureema was supported for this work by a scholarship from the Libyan government. The authors have no conflicts of interest to declare. 


\section{REFERENCES}

Baseggio, N., P. D. Mansell, J. W. Browning, and G. F. Browning. 1997. Strain differentiation of isolates of streptococci from bovine mastitis by pulsed-field gel electrophoresis. Mol. Cell. Probes $11: 349-354$.

Bradley, A. J. 2002. Bovine mastitis: An evolving disease. Vet. J. 164:116-128.

Breen, J. E., M. J. Green, and A. J. Bradley. 2009. Quarter and cow risk factors associated with the occurrence of clinical mastitis in dairy cows in the United Kingdom. J. Dairy Sci. 92:2551-2561.

Charman, N., R. Dyson, A. Hodge, N. Robertson, and S. Chaplin. 2012. A survey of mastitis pathogens in South-Eastern Australian dairy industry. Countdown Symposium, Melbourne, Australia.

Coffey, T. J., G. D. Pullinger, R. Urwin, K. A. Jolley, S. M. Wilson, M. C. Maiden, and J. A. Leigh. 2006. First insights into the evolution of Streptococcus uberis: A multilocus sequence typing scheme that enables investigation of its population biology. Appl. Environ. Microbiol. 72:1420-1428.

Döpfer, D., H. W. Barkema, T. J. Lam, Y. H. Schukken, and W. Gaastra. 1999. Recurrent clinical mastitis caused by Escherichia coli in dairy cows. J. Dairy Sci. 82:80-85.

Douglas, V. L., S. G. Fenwick, D. U. Pfeiffer, N. B. Williamson, and C. W. Holmes. 2000. Genomic typing of Streptococcus uberis isolates from cases of mastitis, in New Zealand dairy cows, using pulsedfield gel electrophoresis. Vet. Microbiol. 75:27-41.

Feil, E. J., and M. C. Enright. 2004. Analyses of clonality and the evolution of bacterial pathogens. Curr. Opin. Microbiol. 7:308-313.

Field, T. R., P. N. Ward, L. H. Pedersen, and J. A. Leigh. 2003. The hyaluronic acid capsule of Streptococcus uberis is not required for the development of infection and clinical mastitis. Infect. Immun. 71:132-139.

Hassan, A. A., I. U. Khan, A. Abdulmawjood, and C. Lammler. 2001. Evaluation of PCR methods for rapid identification and differentiation of Streptococcus uberis and Streptococcus parauberis. J. Clin. Microbiol. 39:1618-1621.

Jayarao, B. M., E. E. Schilling, and S. P. Oliver. 1993. Genomic deoxyribonucleic acid restriction fragment length polymorphism of Streptococcus uberis: Evidence of clonal diversity. J. Dairy Sci. 76:468-474.

Khan, I. U., A. A. Hassan, A. Abdulmawjood, C. Lammler, W. Wolter, and M. Zschock. 2003. Identification and epidemiological characterization of Streptococcus uberis isolated from bovine mastitis using conventional and molecular methods. J. Vet. Sci. 4:213-224.

Lasagno, M. C., E. B. Reinoso, S. A. Dieser, L. F. Calvinho, F. Buzzola, C. Vissio, C. I. Bogni, and L. M. Odierno. 2011. Phenotypic and genotypic characterization of Streptococcus uberis isolated from bovine subclinical mastitis in Argentinean dairy farms. Rev. Argent. Microbiol. 43:212-217.

Leigh, J. A. 1999. Streptococcus uberis: A permanent barrier to the control of bovine mastitis? Vet. J. 157:225-238.

Leigh, J. A., J. M. Finch, T. R. Field, N. C. Real, A. Winter, A. W. Walton, and S. M. Hodgkinson. 1999. Vaccination with the plas- minogen activator from Streptococcus uberis induces an inhibitory response and protects against experimental infection in the dairy cow. Vaccine 17:851-857.

Li, W., D. Raoult, and P. E. Fournier. 2009. Bacterial strain typing in the genomic era. FEMS Microbiol. Rev. 33:892-916.

McDougall, S., D. G. Arthur, M. A. Bryan, J. J. Vermunt, and A. M. Weir. 2007. Clinical and bacteriological response to treatment of clinical mastitis with one of three intramammary antibiotics. N.Z. Vet. J. 55:161-170.

McDougall, S., T. J. Parkinson, M. Leyland, F. M. Anniss, and S. G. Fenwick. 2004. Duration of infection and strain variation in Streptococcus uberis isolated from cows' milk. J. Dairy Sci. 87:20622072 .

Phuektes, P., P. D. Mansell, R. S. Dyson, N. D. Hooper, J. S. Dick, and G. F. Browning. 2001. Molecular epidemiology of Streptococcus uberis Isolates from dairy cows with mastitis. J. Clin. Microbiol. 39:1460-1466.

Pullinger, G. D., T. J. Coffey, M. C. Maiden, and J. A. Leigh. 2007. Multilocus-sequence typing analysis reveals similar populations of Streptococcus uberis are responsible for bovine intramammary infections of short and long duration. Vet. Microbiol. 119:194-204.

Rato, M. G., R. Bexiga, S. F. Nunes, L. M. Cavaco, C. L. Vilela, and I. Santos-Sanches. 2008. Molecular epidemiology and population structure of bovine Streptococcus uberis. J. Dairy Sci. 91:45424551.

Runciman, D., J. Malmo, and M. Deighton. 2010. The use of an internal teat sealant in combination with cloxacillin dry cow therapy for the prevention of clinical and subclinical mastitis in seasonal calving cows. J. Dairy Sci. 93:4582-4591.

Shum, L. W. C., C. S. McConnel, and J. K. House. 2009. Environmental mastitis in intensive high-producing dairy herds in New South Wales. Aust. Vet. J. 87:469-475.

Smith, C. L., and C. R. Cantor. 1987. Purification, specific fragmentation, and separation of large DNA molecules. Methods Enzymol. 155:449-467.

Tenover, F. C., R. D. Arbeit, R. V. Goering, P. A. Mickelsen, B. E. Murray, D. H. Persing, and B. Swaminathan. 1995. Interpreting chromosomal DNA restriction patterns produced by pulsed-field gel electrophoresis: Criteria for bacterial strain typing. J. Clin. Microbiol. 33:2233-2239.

Wang, S. M., M. A. Deighton, J. A. Capstick, and N. Gerraty. 1999 Epidemiological typing of bovine streptococci by pulsed-field gel electrophoresis. Epidemiol. Infect. 123:317-324.

Zadoks, R. N., Y. H. Schukken, and M. Wiedmann. 2005a. Multilocus sequence typing of Streptococcus uberis provides sensitive and epidemiologically relevant subtype information and reveals positive selection in the virulence gene pauA. J. Clin. Microbiol. 43:2407-2417.

Zadoks, R. N., L. L. Tikofsky, and K. J. Boor. 2005b. Ribotyping of Streptococcus uberis from a dairy's environment, bovine feces and milk. Vet. Microbiol. 109:257-265. 